Psychology of Language and Communication 2013, Vol. 17, No. 2

VERSITAOPEN

DOI: $10.2478 /$ plc-2013-0011

\author{
MARCIN MIEKOWSKI \\ Polish Academy of Sciences, Warsaw
}

\title{
ON THE SOCIAL NATURE OF LINGUISTIC PRESCRIPTIONS
}

\begin{abstract}
The paper proposes an empirical method to investigate linguistic prescriptions as inherent corrective behaviors. The behaviors in question may but need not necessarily be supported by any explicit knowledge of rules. It is possible to gain insight into them, for example by extracting information about corrections from revision histories of texts (or by analyzing speech corpora where users correct themselves or one another). One easily available source of such information is the revision history of Wikipedia. As is shown, the most frequent and short corrections are limited to linguistic errors such as typos (and editorial conventions adopted in Wikipedia). By perusing an automatically generated revision corpus, one gains insight into the prescriptive nature of language empirically. At the same time, the prescriptions offered are not reducible to descriptions of the most frequent linguistic use.

Key words: descriptivism, prescriptivism, normativity, corpora research, Wikipedia
\end{abstract}

In linguistics, there is a controversy over the status of prescriptive rules of usage. Some descriptive linguists claim that popular style guides (e.g. Strunk 1918) offer prescriptions that tend to be arbitrary, conservative and outdated, and that the ultimate source of the prescription should be the real-life use of language. Yet it seems that some linguistic errors - or uses perceived as errors by most language users - are stable phenomena in language, which does not make them automatically correct. In particular, none of the frequent mechanical errors seem to become correct: "teh" is never considered a correct variant of "the".

In this paper, I analyze the nature and function of linguistic prescriptions. Simple approaches, such as corpora-based descriptivism and expert-authoritybased prescriptivism, seem to ignore the dynamics of language change. Descriptivism cannot account for the fact that users seem to be quite emotionally involved in the controversies over correct use, which do not seem to be limited to linguistic purists only. Moreover, not all stable linguistic patterns of use have

Address for correspondence: Marcin Miłkowski, Institute of Philosophy and Sociology, Polish Academy of Sciences, Nowy Świat 72, 00-330 Warsaw, Poland. E-mail: mmilkows@ifispan.waw.pl 
a chance to become standard, even when they become statistically salient. Prescriptivism cannot account for the simple fact that users do not always rely on experts' authority when debating over use and it does not explain why some but not all prescriptions are consistently ignored by most users.

What both approaches lack is the account of the social behavior of language users. The prescriptions used explicitly by users are not justified in a single way but by referring to multiple sources, and the sources might include linguistic experts (including official prescriptive bodies), the use as found in popular writers or intellectual élite, or simply frequency of usage (cf. Rudnicka 2007). At the same time, there are corrective behaviors that need not be supported by any explicit knowledge of the rules being used. These behaviors, however, seem to be insufficiently investigated and analyzed in linguistic research.

The goal of this paper is to show that there is a way to discover prescriptions empirically as they are perceived in implicit normative judgments of language users. To do so, I also need to vindicate the notion of a linguistic prescription, which has been criticized as unclear and in need of clarification. The method of justification I propose is based on an account of linguistic prescription as a social coordination of action - in this case, the action is also linguistic.

\section{Prescriptivism and descriptivism}

The discussion over prescription in linguistics is dominated by two positions: prescriptivism and descriptivism. The latter claims that prescriptions offered by linguists, if they clash with the stable use patterns of language, cannot be justified. The former claims that there is a standard that one can use to judge whether an utterance is linguistically correct or not, and the statistics of use are of no import for deciding the correctness. In today's linguistics, especially in its corpora-based parts, descriptivism seems to be dominant (Finegan, 2003). It seems to be correct as far as it criticizes the prescriptions that are not justified with any empirically testable methodology. Many traditional prescriptions are indeed unjustified (such as the traditionally criticized Polish expressions "alternatywa" [alternative] and "w międzyczasie" [in the meantime]: they have no correct counterparts that one could use instead; see Bańko, 2008). At the same time, it does not come to grips with linguistic reality.

In reality, language users at least on some occasions tend to ask linguists how to use the language, which is especially obvious in Poland, where numerous linguistic advisory websites - mostly academic or connected to scientific publishers - were created and remain very popular. Why would they do that if use is what sets the linguistic standard? Do speakers of Polish suffer from a massive delusion? Moreover, users tend to get emotional over the correctness of linguistic forms. An attempt to explain this emotional reaction with personality traits (Bańko, 2008: 5) is utterly misplaced, however. Even if personality traits 
increase the chance that someone will criticize incorrect language use, it does not explain why it is language use rather than, say, ability to bake muffins or to solve complex mathematical problems that is the focus of the criticism. In other words, while personality traits may play some role, it is quite obvious that their role is not directly causal, as they do not explain why it is linguistic behavior that we get emotional over - and not something else (I assume here the interventionist concept of causal explanation; for details about contrast classes in causal explanation, see Woodward, 2003).

Granted, there is a significant social background that explains why in some periods, prescriptions become more popular. For example, campaigns for national unification and integration usually want to limit linguistic variation; witness the popularity of prescriptivism in America in the 19th century (Drake, 1977). It is even more obvious for French speakers: after the Revolution, the prescriptive standards became mandatory for everyone who wanted to be 'French' and 'reasonable' (Lodge, 1991). The descriptivist might say that prescriptivism is true in societies where it was widely disseminated. But why was it catchy? This remains unclear.

The dichotomy between prescriptivism and descriptivism is, however, a false one. "Use" is an extremely vague concept: it is not clear what we should look at exactly when we want to accept language use as the only norm of correct usage. It cannot be simply "frequent use," nor "statistically relevant use," as some frequently used forms do not necessarily become accepted as correct. For example, "teh" is not even a candidate that could be accepted just as well as "the". If you input Polish "wogle" in Google, you will not get the correct form ("w ogóle" [at all]) as a suggestion, as the incorrect form is already abundant in everyday use. Nobody, however, ever suggested that it should be accepted as it violates the rules of spelling and pronunciation (it is "ogóle", not "ogle"), and mangles the whole expression into an incomprehensible blob. It seems pretty clear that if we want to justify normative judgments about the use of language, we have to go beyond the description of frequent, or statistically relevant, linguistic patterns (important as they are).

It is at the same time clear that traditional prescriptivism is no longer tenable. It was too selective and arbitrary (Bańko, 2008), and criticized stable forms such as "w międzyczasie" or English split infinitives on quite dubious grounds. People ignored these criticisms altogether, so such prescriptions fall on deaf ears. Moreover, many prescriptions get outdated quickly when language develops, and become empty. For example, Polish dictionaries criticized the bureaucratic newspeak of the official propaganda that was prevalent in the official register of Polish. Today, this kind of newspeak, inspired by Soviet propaganda, is extinct. Yet, instead of criticizing the newspeak of modern marketing and $\mathrm{PR}$, dictionaries get reprinted with the same outdated material. So if the prescription is to work, it has to be in contact with the current form of language, and it has to deal with errors which are perceived as errors. Otherwise, it will be either vacuous or ignored by users. 
The way prescriptive linguists justify their correctness judgments is, however, much more complicated than the above caricature. What seems important is that prescriptive linguists use many (and sometimes multiple) criteria to evaluate whether a given case of language use is correct. In a recent review paper (Rudnicka, 2007), the number of criteria as used by Polish linguists in theoretical papers was reported to be as high as 60 ! They tend to focus on history, simplicity, frequency of forms, usefulness in communication, and adherence to a grammatical system. Nevertheless, some judgments still seem arbitrary, as usefulness is hard to evaluate in a simple way. Additionally, the list contains criteria that seem to be disconnected and it is hard to understand what their deep relationship is (if any). What is needed, therefore, is a quantitative way that would enable to weigh different sociolinguistic trends of use and choose the dominant forms; a method to find out what people find correct and what they deem incorrect.

\section{Linguistic normativity as based on social coordination}

To know how to justify linguistic prescriptions, we need to know when they are used, or what role they play in the linguistic ecosystem. Speakers want to know whether language use is correct in various cases: when learning or acquiring a language; when introducing innovations; when some parts of language are no longer used; when a construction is a rarity, etc.

I claim that the main function of prescriptions is to maintain the stability of language in the face of numerous mutations and changes. Prescriptions effectively filter out some confusing aspects of language use, and could be seen as a (partially artificial) selection of language forms. Natural linguistic processes lead to variability via mutations, which may sometimes be random, and prescriptions help retain stability of the conventional system of communication.

One can distinguish several kinds of linguistic prescriptions, or norms inherent in language:

(1) prescriptions actively advocated,

(2) prescriptions elicited by asking,

(3) prescriptions recognized if asked,

(4) prescriptions used in behavior.

Note that these are quite different kinds of norms with respect to their cognitive status. The prescriptions one actively advocates could be completely new principles that lead to an innovation in language (usually under the banner of "conservation" or "tradition"). For example, a campaign against words borrowed from other languages will be accompanied by such prescriptions, and they will not be, in the proper sense, the already existing rules of a language, i.e. rules that one needs to observe to speak this language. In this case, the user cannot be said to know that these prescriptions are binding; he or she only wants them to be binding. 
The second category concerns the prescriptions a user formulates when asked by a linguist. The process of elicitation, however, might easily bias the user towards rationalizing: native speakers usually offer some explanations for surface differences they observe in the language, even when there is no evidence that the difference is reflected in any way in the typical use. Though traditionally it is presupposed that elicited norms are justified by "linguistic intuition" (see e.g. Itkonen, 2008), I suggest that this is a misnomer. Such rationalizations need not be considered infallible, especially when the very process of elicitation might create artifacts.

Linguistic behavior is generated by cognitive mechanisms on the tacit level of know-how, rather than on the know-that level of declarative knowledge, and there is a large gulf between the two. Even if the user is not asked to formulate a rule but to say whether a sentence is correct (to offer a grammaticality judgment), the very question might bring concerns that are not usually taken into account during language production; it will inevitably create some bias, most of the time towards something that the user thinks is the "official" register. Moreover, the selection of the sentences to be judged by users has to be balanced and properly sampled; otherwise, this will create another bias. So even if the elicited prescriptions are not as arbitrary as the ones that are being advocated for, they are at best widely held convictions about what is a prescription in the language. The same holds for prescriptions that would be recognized by users of language if they were asked to do so. In this case, we do not have to worry that they rationalize; yet they have to judge the rationalization offered. Theoretical bias is still there.

The only case when we can speak of knowledge embodied in prescriptions is when a behavior is compatible with prescriptions (note: I do not presuppose whether language is actually generated with a rule-based cognitive process or not). In this case, we can say that a prescription that has no counterpart in reallife linguistic behavior is a theoretical artifact. Conversely, a prescription that is validated by behavior is binding in the language: users behave regularly in such a way as if the prescription was the basis for their behavior, so the prescription in this case is a true description of the pattern in their behavior, and it can be used reliably to predict future behavior. For this reason, the prescriptions are also knowledge: they are models of true, reliable (though tacit) beliefs of users. (Here, I assume the reliabilistic account of knowledge, i.e. the claim that any true belief which stems from a reliable cognitive process is knowledge, see Goldman, 1994. ${ }^{1}$ )

\footnotetext{
1 The argument does not depend on reliabilism. It is just easier to articulate in this form; one could also run it in non-naturalized epistemology, where justification is rendered as a kind of evidential relation (like obviousness). It is quite clear that users find rules of language that they actually follow obvious and not in need of further justification. Yet, in the case of internalist epistemology, various skeptical problems may arise: individual intuition may be challenged by the private language argument and the likes. Note that the social accounts of knowledge are less prone to such a skeptical objection: individuals might err as often as they like but it is utterly implausible that they will do so in the same way all the time, and we look at patterns of collective behavior, so errors in detecting errors actually cancel each other out.
} 
If users adhere to a prescription, then they know that it is binding. And when they know that the rule is binding, the rule is binding just because it is knowledge.

So while this is an inference from "is" to "ought," from linguistic facts to linguistic prescriptions, it is perfectly valid. It is not an example of any naturalistic fallacy, as these facts are already social, or institutional facts, and institutional facts support normative inferences (see Searle, 1995 for more). By observing linguistic behavior, we may therefore infer what rules are valid in the language.

There are two reliable sources of such knowledge embodied in linguistic behavior: standard linguistic corpora that bring positive examples of real-life use, and error corpora that contain negative examples. Standard corpora contain patterns that may be discovered using various statistical tests and machine learning algorithms, besides human-work-based methods. Yet the rules discovered might be overly general: they would not explicitly say what is prohibited in the language. To know that we need to go beyond them: we need error corpora that contain the statistically relevant, frequent mistakes that people are prone to make but which are actually considered mistakes. So by looking at these mistakes, we can restrict the scope of the positive rules. In other words, standard corpora are the basis for positive prescriptions, and error corpora - for negative ones. They both contain social common knowledge - tacit, or implicit in our everyday use of language. And this is why they can justify the prescriptions: no prescription can be justified by mere individual intuition; mere individual intuition, criticized in fact by Wittgenstein in his private language argument, is never enough to be a criterion of correct usage (Itkonen, 2008).

Yet, to be appropriate for justifying the prescriptions, error corpora must be bootstrapped from the linguistic behaviors themselves. Manual annotation of school tests by teachers, for example, would mean biasing the error corpus in favor of the rules of grammar and style officially required from learners. The only way to avoid such bias is to create a corpus based on patterns of statistically salient corrective behavior.

Most language users tend to correct typos, grammatical mistakes or other linguistic blunders. Obviously, this will happen when parents interact with their children, but this is not the only situation when it occurs. The process of language acquisition is just one of the processes when we care about correct use. There are multiple other situations where correctness is highly prized: a funny typo in a company logo might even ruin it; we constantly edit documents to make them better, and so on.

The normativity of a prescription is inherent in the social coordination whose form is the standard linguistic use constrained by corrective behavior. In other words, the justification of a prescription in a language is the fact that its users behave as if they followed this prescription by using the language and by correcting others. Note that the users do not need to be aware of the prescription they follow in both cases. No single individual needs to be aware of the complexity 
of prescriptions people are using, just as no single individual needs to know all the words of a language. All that is important is the relevant pattern in the collective behavior of most users. If we look at the corrective behaviors as a whole, there will be trends involved: some mistakes are corrected more often and sooner than others. We no longer have to rely on explicit grammaticality judgments of individuals to justify prescriptions.

A disclaimer is in place here. Though I use the words "prescription," "norm" and "rule" interchangeably in this paper, I do not mean to say that prescriptions are symbolic rules in the spirit of traditional cognitivism. Actually, in this account, I do not want to take that any modeling tool is the only one that should be used to describe prescriptions in general. In this regard, the choice should be pragmatic. If the goal of modeling is to build an automatic tool that will use the prescriptions to annotate text or to predict trends in behavior, it may as well use a connectionist network or any statistical machine learning algorithms. If the goal is to build a cognitive model of correcting behavior, a more realistic mechanism should be used, and more experimental evidence might be needed (various measures of tacit behavior could be useful to constrain the space of possible models, e.g. eye tracking; EEG; chronometry; neuroimaging). And if the goal is to offer advice to foreign learners who want to know how the native speakers of a language evaluate certain forms, then the model should either be built in terms understandable to most people (i.e., rules of school grammar), or give simple examples from the corpus that would be easy to grasp. The way one models collective behavior and the prescriptions inherent in it should simply be geared towards the use of the model. All I require is that the models be evaluated using standard measures (like accuracy, precision, and recall) used in such cases.

I also remain relatively neutral as to the nature of the implicit knowledge embodied in distributed, collective linguistic behavior. It is not reducible to the behavior of a single individual, yet I do not presuppose any linguistic theory here. I do not want to decide what is the actual nature of the implicit knowledge in this paper (for a general outlook of methodologies that explain behavior with implicit knowledge, see Miłkowski, 2008b).

The norms implicit in utterances and the corrections proposed by users tend to evolve over time, as people react to what others do. As Soviet newspeak is used almost only ironically in Polish, nobody would bother to correct it (doing so would mean not understanding the joke). So if we focus on corrections that are actually made in contemporary language, we will not find outdated norms that fill the pages of old style guides.

There might be different grounds for corrections in various cases. I do not suggest that all there is to prescriptions is that people start correcting each other out of the blue: users do consult dictionaries when correcting and they also discuss the correctness among themselves. The suggestion is that people use multiple sources to make sure that their usage is correct (and this is why prescriptivist 
linguists have so many criteria in practice: they are not omniscient, so they refer to different kinds of evidence, see the section above), and that also includes linguistic prescriptions offered by dictionaries or official bodies. My account does not propose that the content of prescription is to be found in a single source; rather, I claim that the validity of the prescription is a matter of whether there is a trend in collective behavior or not. If few people (or none) follow a prescription in their corrective behavior, a given prescription is no longer binding in the language. There is a place for a gray area of prescriptions that are used by some people but disregarded by others: this is where a change may take place in the language.

There are, obviously, some prescriptions that are followed by different social groups: high social status and education results in more corrections than low social status and no education. Using trends in collective behavior, we may look at groups defined in more fine-grained fashion than the whole linguistic community.

An important aspect of corrective behaviors is that the social interaction is usually asymmetrical: if the error is not just a technical mistake (a typo or a slip of the tongue) but a cognitive mistake, we may assume that the user that discovers the error is more competent than the user that made the mistake. After all, the mistake stems from their lack of cognitive competence: incomplete knowledge that some utterance or form is wrong. And the corrections presuppose implicit knowledge of what is correct. So there is a certain form of knowledge asymmetry in such a case. From a sociological point of view, this implies different status, or power positions (Lodge, 1991), and this may explain the emotional overtones of discussions over correct use.

\section{A corpora-based method to investigate the implicit norms}

To know what constitutes a prescription, understood as in the previous section, we need a standard corpus and an error corpus. The standard corpora are not a problem: for most languages, they are already available. The traditional way to prepare an error corpus is to manually annotate it with extended information on grammar mistakes, style abuses, misspellings, typos, etc. The manual annotation requires that the corpus be prepared by a qualified linguist or a language professional (a proofreader in a publishing house, a reviewer in a translation agency etc.) This, however, means that collecting a large error corpus will be time- and resource-consuming. There were some small corpora collected this way for Polish (Pisarek, 1978 is a dictionary based on sampling newspaper texts). In the case of creating larger corpora, the costs could turn out prohibitive. Moreover, manually annotated corpora will inevitably be biased by the choices of the annotators.

Nonetheless there is a large source of cheap empirical data ready to use: we can look at how texts are corrected by average users over long periods of time. Computer technology makes this method much easier to use, especially when 
we have some version tracking in place: when subsequent edits are recorded as a history of the text. Such version tracking systems can be used in word processors where multiple people edit the same document, and it is indispensable for creating a document in a multi-user environment. No wonder that Wikipedia has its version tracking mechanisms.

A method that uses version tracking as the starting point was used to gather very detailed data for LanguageTool, an open-source proofreading tool (for more technical information, see Miłkowski, 2010). Before I go into the detail of the method, let me give some background information about the proofreading tool itself. It is used as a plugin in many computer applications that help users to correct text, from vim and LibreOffice to LyX and Thunderbird. There is also a special version for translators that helps to discover common problems with translated text (in OmegaT or in CheckMate). The proofreading tool is based on surface text processing, without deep parsing, not to mention semantic analysis. Nevertheless it manages to get significantly better results for some languages than commercially available products (see Miłkowski, 2010 for a comparison for Polish).

LanguageTool is a rule-based checker that detects patterns defined over tokens in a sentence: the input text is segmented into individual sentences (Miłkowski \& Lipski, 2011) and then analyzed morphosyntactically and lemmatized. Then error rules are matched to all sentences, and matches are presented to the user, along with a suggestion of a correction (when possible). As of the time of writing this paper (August 2013), 29 languages are supported to different degrees. To build such a tool, one needs to incorporate non-controversial views on prescription. That is the theoretical interest in investigating this matter empirically. The more practical aspect is that such investigation might help to build rules semi-automatically from corpora (see Miłkowski, 2011).

Let me return to the method of acquiring the information on prescriptions from empirical data, viz. data on version tracking. The basic idea is that frequent changes of short strings in documents usually reflect either editorial conventions or linguistic norms (Miłkowski, 2008a). As Wikipedia contains version tracking mechanisms, it was a natural candidate for experiments. Though its revision history is large (2,440 million words), it is still incomplete for our purposes: it gathers a lot of material, but the changes themselves are not so numerous. But with time, it becomes more and more interesting.

It is quite easy to prepare a corpus of frequent revisions for Wikipedia, and the method works for many languages. By using this corpus, I was able to automatically generate formal rules used to detect errors (note: a slightly more complex but statistically more reliable method is to use error information to distort a clean large corpus and learn rules from the distorted corpus, cf. Miłkowski, 2011). Note that this is not possible if we start with "normal" prescriptive material, as human-readable dictionaries omit a lot of information which is "obvious" to the 
Table 1. Most frequent single word changes in Polish Wikipedia

\begin{tabular}{lccc}
\hline$\#$ & Original & Correction & Frequency \\
\hline 1 & województwie & województwa & 26162 \\
2 & & - & 16003 \\
3 & zamieszkiwało & zamieszkiwały & 2738 \\
4 & zamieszkiwały & zamieszkiwało & 2646 \\
5 & podstawowe & przegląd & 2519 \\
6 & sie & się & 2343 \\
7 & & & 1854 \\
8 & tė: & té & 1760 \\
9 & $(\dagger$ & (zm. & 1753 \\
10 & Gmina=Saint & Gmina=Saint & 895 \\
11 & także & też & 851 \\
12 & & w & 834 \\
13 & - & & 797 \\
14 & to & - & 762 \\
15 & to & Edward & 587 \\
16 & E. & & 584 \\
17 & & & 512 \\
\hline
\end{tabular}

reader. Most of the time, instead of a complete rule, an incomplete example is given, and it may be ambiguous or leave out some exceptions that linguists fail to mention. The method I am using creates very detailed and complete descriptions of mistakes as well as complete descriptions of corrections, so ambiguity is no longer a problem. Table 1 lists the most popular changes of a single word in the error corpus I built (taken from Miłkowski, 2008a).

The top frequent changes also reflect the editorial conventions in Wikipedia (e.g. \#5 "podstawowe informacje" [basic info] was changed to "przegląd" [overview]), but this is not a disadvantage of this method: we see how much of the explicitly given conventions are actually used in practice, and in the case of a different version tracking system we might discover other editorial conventions by looking at correction patterns as well.

Most other revision patterns reflect the rules implicit in typical language behavior, though it is typos that we fix most frequently (\#6 is "sie" changed to "się"), and style changes ("także" [also] changed to "też" [too]). The implicit character of the prescription is a feature of this method: instead of asking users how they evaluate an utterance, which may prompt them to give a random evaluation if 
they are not sure, and bias the results by directing their attention to something they might normally ignore, we focus on what is done in their normal environment rather than in a lab.

By looking at what people do correct, we can see two general categories: mechanical and cognitive mistakes. Mechanical mistakes (like writing "teh" instead of "the," if not meant as a joke) do not seem to become an accepted standard, as they are not considered correct even by the people that make them. Cognitive mistakes (like writing "your an idiot") are more interesting, as they may become accepted as innovations. Based on the correction, it is not always possible to tell whether a given mistake was a mechanical typo or a cognitive mistake: the boundary is somewhat blurry, and is meant as a heuristic. For example, one letter might be missing in a word both when someone does not know how to conjugate verbs and when they have poor typing skills. The distinction is clearer in the case of longer expressions that are used incorrectly by incompetent speakers: individual slips of the tongue cannot explain relevant statistical trends in errors that seem to be popular.

By looking at the corrections, we find that some errors do not result in very clear patterns of correction. For example, Polish rules of punctuation are quite complex and the linguistic behavior seems to be irregular: nowadays, it is usually influenced by English punctuation rules. This pertains also to corrections. However, people still know how to use spaces (\#7 and \#8 are about adding a space in the proper place, though you cannot see this in print).

Some cognitive mistakes, such as confusing "pełnić funkcję" [serve a function] and "odgrywać rolę" [play a role] in the expression "pełnić rolę" [serve a role], are usually left uncorrected. There is empirical evidence that this form is becoming accepted, and this might be used to defend it against the old prescriptions printed in usage dictionaries. It seems that this confusion does not have any unneeded consequences: there is no problem with additional ambiguity in communication, and it is not really an exception to the general rules of language, so it does not make learning Polish all that much harder.

\section{Conclusion}

The norms implicit in language use can be investigated indirectly by looking at corrections proposed by language users. Using automatic methods, we can generate a corpus of what is usually considered a mistake. The investigation is quantitative, and not only qualitative as in traditional prescriptivism, so we may observe the trends in a much more detailed fashion. One might read this as a limited defense of prescriptivism, but the notion of prescription that I vindicate is based on what is perceived as an error by language users. In other words, without the true description of the language usage patterns, the method would not work. So in this respect, I defend a grain of truth in descriptivism as well. 
The results suggest that people do not simply accept all frequent errors and tend to treat some apparent cognitive mistakes as correct. This means that unconstrained descriptivism, if it is the claim that all that prescriptions are is a description of frequent use, is simply false. People go beyond frequency.

On a more abstract level, my view is that the normativity of language depends on what its users know about norms. They do not need to bring them into focus and reflect on them; it is enough if they behave as if they did. It is more plausible to suggest that most prescriptions are based on implicit beliefs about correctness. It is not linguists or logicians, or whatever experts, who decide what is correct arbitrarily on their own. Just because users know that a prescription is binding in the language, and we can see that they reliably behave as if they did, we may infer that the prescription is binding. So in this case the inference from "is" to "ought" is made possible thanks to the linguistic, though implicit, knowledge of speakers. Empirical observation can therefore be used to justify the prescriptions, and we can use a quantitative measure of a model prescription's match to real-life material (its accuracy in a given group, time, place, etc.). In other words, models of prescriptions (whatever formalism or technique was used) can be evaluated in a quantitative, standardized way.

Correctness is the outcome of a complex process of interaction, which sometimes gets hot and emotional. My suggestion is also that a proposed correction might be interpreted as deflating someone's social status, and this might explain some of the emotional overtones in the discussions over correctness. It is clear that speakers care about the correctness of use, and they go to a lot of trouble to act as filters for innovations and linguistic variation in general.

\section{Acknowledgement}

The research on this paper was financed by the grant from the Polish Ministry of Science and Higher Education N N101 138039.

\section{References}

Bańko, M. (2008). O normie i błędzie [On norms and errors]. Poradnik fęzykowy, 5, 3-17. Drake, G. (1977). American linguistic prescriptivism: Its decline and revival in the 19th century. Language in Society, 6 (03), 323-340.

Finegan, E. (2003). Linguistic prescription: Familiar practices and new perspectives. Annual Review of Applied Linguistics, 23, 213-224.

Goldman, A.I. (1994), What is justified belief. In H. Kornblith (Ed.), Naturalizing Epistemology (pp. 105-130). Cambridge: MIT Press.

Itkonen, E. (2008). The central role of normativity in language and linguistics. In J. Zlatev, T.P. Racine, C. Sinha, \& E. Itkonen (Eds.), The Shared Mind: Perspectives on Intersubjectivity (pp. 279-305). Amsterdam: John Benjamins. 
Lodge, R. (1991). Authority, prescriptivism and the French standard language. fournal of French Language Studies, 1, 93-111.

Miłkowski, M. (2008a). Automated building of error corpora of Polish. In B. Lewandowska-Tomaszczyk (Ed.), Corpus Linguistics, Computer Tools, and Applications - State of the Art. PALC 2007 (pp. 631-639). Frankfurt am Main: Peter Lang.

Miłkowski, M. (2008b). Postulowanie utajonych funkcji umysłu: realizm kontra antyrealizm [Positing latent functions of the mind: realism versus antirealism]. In S. Wróbel (Ed.), Utajone funkcje mystu [Latent Functions of the Mind] (pp. 15-37). Poznań: Wydział Pedagogiczno-Artystyczny UAM.

Miłkowski, M. (2010). Developing an open-source, rule-based proofreading tool. Software - Practice and Experience, 40 (7), 543-566.

Miłkowski, M. (2011). Automating rule generation for grammar checkers. In S. Góźdź-Roszkowski (Ed.), Explorations Across Languages and Corpora. PALC 2009 (pp. 123-133). Frankfurt am Main: Peter Lang.

Miłkowski, M. \& Lipski, J. (2011). Using SRX standard for sentence segmentation. In Z. Vetulani (Ed.), LTC 2009, Lecture Notes in Artificial Intelligence 6562 (pp. 172-182). Berlin: Springer.

Pisarek, W. (1978). Stownik języka niby-polskiego, czyli błędy językowe w prasie [Dictionary of Quasi-Polish, or Linguistic Errors in the Press]. Wrocław: Ossolineum.

Rudnicka, E. (2007). O kryteriach oceny poprawności językowej i ich roli w warsztacie współczesnego językoznawcy normatywisty [On the criteria of language correctness and their role in the methodology of contemporary normative linguists]. Przeglad Humanistyczny, 2007 (3), 111-120.

Searle, J. (1995). The Construction of Social Reality. New York: The Free Press.

Strunk, W. (1918). The Elements of Style. Ithaca, NY: W.P. Humphrey.

Woodward, J. (2003). Making Things Happen. Oxford: Oxford University Press. 